\title{
Friction coefficient of orthotic foams
}

\author{
R. Cláudio*,***, M. Guedes ${ }^{*, * * *}$, A. Casimiro ${ }^{* *}$, M. Silva ${ }^{* *}$, C. Figueiredo-Pina* \\ * Department of Mechanical Engineering, School of Technology, InstitutoPolitécnico de Setúbal, 2910-761 \\ Setúbal, Portugal. \\ ** School of Technology, InstitutoPolitécnico de Setúbal, 2910-761 Setúbal, Portugal. \\ *** ICEMS, Instituto Superior Técnico, Av. RoviscoPais, 1049-001 Lisboa, Portugal. \\ email: celio.pina@estsetubal.ips.pt
}

Foams are used in the manufacture of orthotics, positioned in the contact regions between the device and patient's skin. Because foams are deformable and compressible, the continued use of the device frequently results in patient discomfort and even pain. Orthotics are most frequently produced using traditional methods, and foam selection is empirical and based on the manufacturer's established practice. A strategy both to systematize orthotics manufacture and to increase patient wellbeing is to properly simulate the orthotics/skin interface, gathering data for an appropriate and systematic correlation between materials selection and the device comfort performance. In this context, the current work proposes to determine the friction coefficient between human skin and synthetic foams. Four different commercial foams were tested. Reciprocating pin-on-plate friction tests were carried out during $30 \mathrm{~s}$ using a human middle finger as plate and foam as pin. The friction tests were carried out under dry and wet conditions, using applied loads between 0.5 and $2 \mathrm{~N}$. The foams were previously submitted to compression test to determine yield stress and elastic modulus. The microstructures were analysed by FEG-SEM and image analysis software was used to derive semi-quantitative information concerning cell dimension and cell wall thickness. Assessed morphological features were correlated with foam properties.

The tested foams differ on cell size, shape and wall thickness (Figure 1). Results obtained through compression tests show higher values of yield strength and elastic modules for the foams with lower cell size (Table 1). The friction coefficient decreases with increasing applied load (Fig. 2) and it is sensitive to the foam thickness and cell structure, especially for low applied loads. The difference between the friction coefficients of tested materials decreases with increasing applied load. Friction coefficients were similar for an applied load of $2 \mathrm{~N}$.

Attained results show that the friction coefficient is sensitive to the mechanical properties, cell structure and thickness of the foam. Appropriate selection of the contact foam thus presents as a simple route for assuring higher comfort levels of patients carrying orthotic devices.

[1] Ramalho A. et al., Wear, 263, 1044-1049, 2007.

[2] Pina C. et al., Proc. Int. Conf. BALTTRIB'2011, 162-166, 2011. 

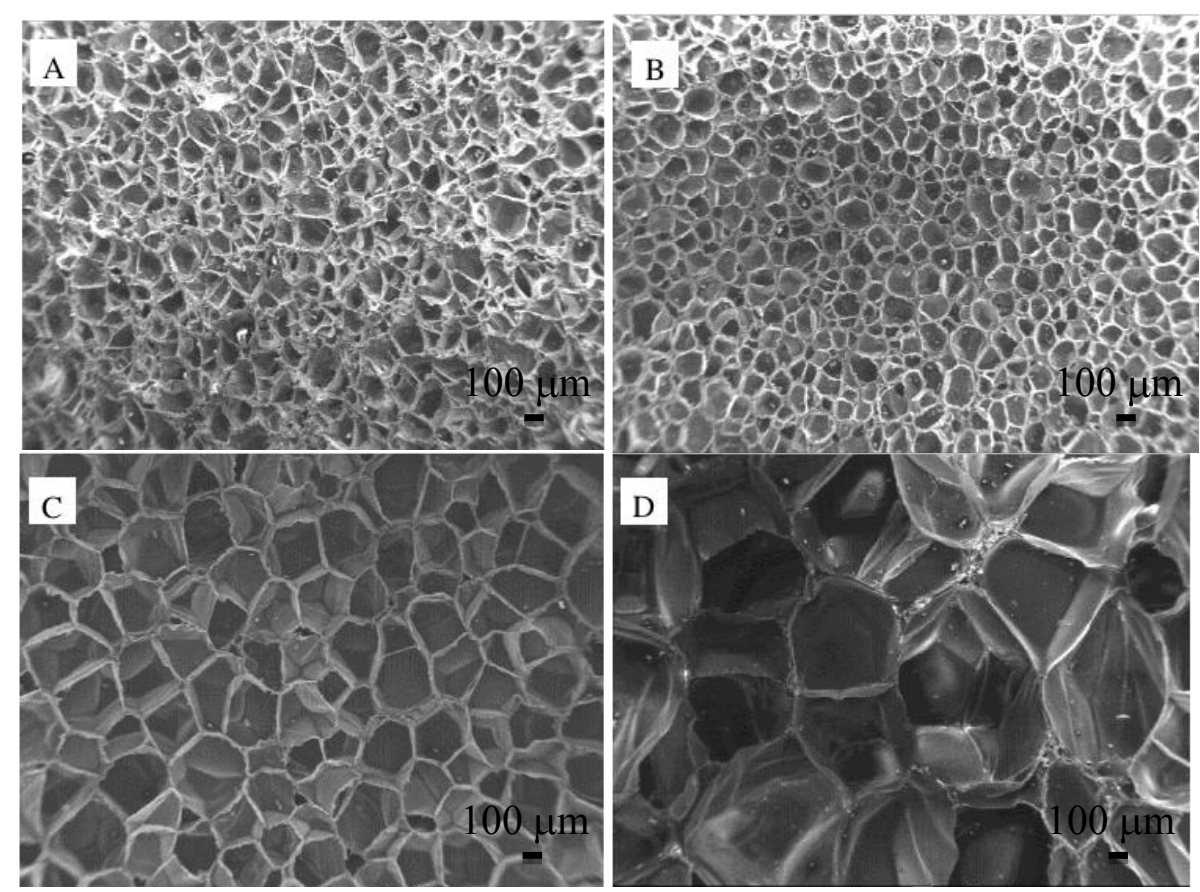

Fig. 1 - Low magnification SEI of the tested foams.

Table 1 - Mechanical properties of the tested foams.

\begin{tabular}{|c|c|c|}
\hline Foam & $\begin{array}{c}\text { Yield stress } \\
(\mathrm{kPa})\end{array}$ & $\begin{array}{c}\text { Elastic modulus } \\
(\mathrm{MPa})\end{array}$ \\
\hline $\mathrm{A}$ & 116.9 & 6.6 \\
\hline $\mathrm{B}$ & 153.7 & 4.3 \\
\hline $\mathrm{C}$ & 35.0 & 0.9 \\
\hline $\mathrm{D}$ & 18.9 & 0.9 \\
\hline
\end{tabular}

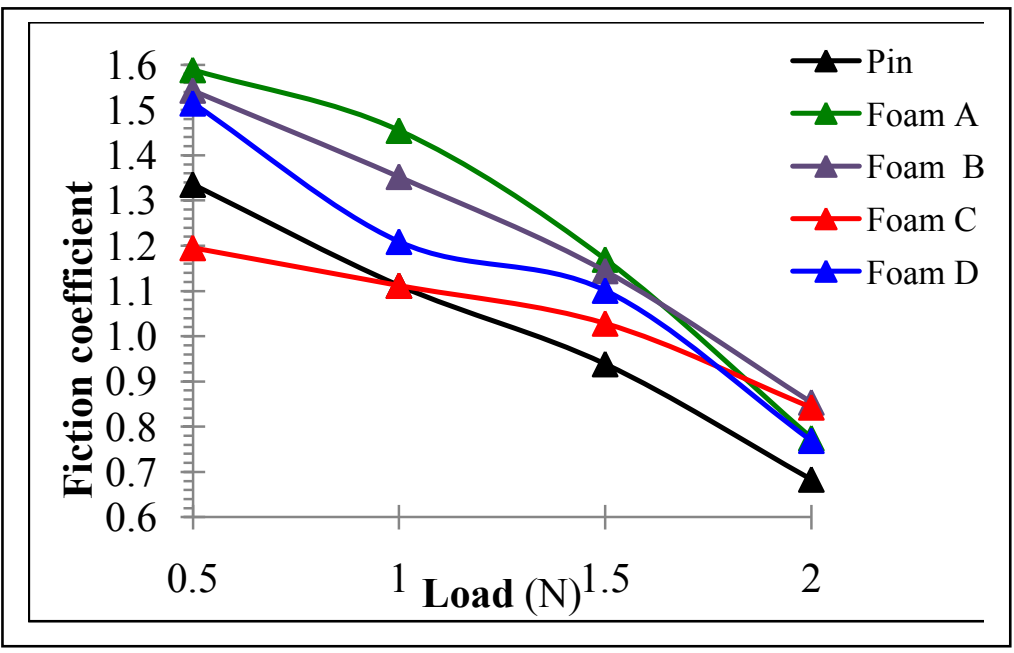

Fig. 2 - Friction coefficient for foam/skin pairs as a function of applied load. 